OPEN ACCESS

Edited by:

Krisztian Kordas,

University of Oulu, Finland

Reviewed by:

Akos Kukovecz,

University of Szeged, Hungary

Emilia Morallon

University of Alicante, Spain

*Correspondence:

Emilia Peltola

emilia.peltola@aalto.fi

Specialty section:

This article was submitted to Translational Materials Science,

a section of the journal

Frontiers in Materials

Received: 14 May 2019

Accepted: 06 August 2019

Published: 21 August 2019

Citation:

Peltola E (2019) Hybrid Carbon

Nanostructures for Direct Neuronal

Interfacing. Front. Mater. 6:202.

doi: 10.3389/fmats.2019.00202

\section{Hybrid Carbon Nanostructures for Direct Neuronal Interfacing}

\author{
Emilia Peltola* \\ Department of Electrical Engineering and Automation, School of Electrical Engineering, Aalto University, Espoo, Finland
}

We have developed a concept of hybrid carbon nanomaterials, where different allotropes of carbon are integrated into a structure. In order to facilitate the long-term measurements in vivo, the cellular response at the bioelectric interface should be optimized. Indeed, failure of implant integration has been proposed to be the main reason for sensor failure in vivo. Most strategies to enhance electrode integration into target tissue exploit a protective layer or barrier on an electrode substrate. For the detection of neurotransmitters, this is not as suitable strategy, because (1) such films give rise to an increased background electrode capacitance and impedance, and (2) act as a diffusion barrier and as a result, a decreased amount of the analyte reaches the electrode surface and the kinetics is compromised. Here we demonstrate that we can regulate the cellular response just with the electrode material. Specifically, we will show that it is possible to combine the properties of different carbon allotropes to obtain hybrid materials with enhanced neural response. We will present three examples of the approach: (i) functionalized nanodiamonds on tetrahedral amorphous carbon (ta-C), (ii) multi-walled carbon nanotubes grown directly on top of ta-C, and (iii) carbon nanofibres synthesized on top of ta- $\mathrm{C}$ thin films. We demonstrate that hybrid structures may promote neural integration as, for example, hydrogen-terminated nanodiamonds enhance neural cell viability and while not increasing glial cell viability. Moreover, carbon nanofibers show prominence for tuning the cellular response as their dimension match biologically relevant cues. We show that nanofiber dimensions significantly alter glial and neural cell adhesion as well as their morphology. The properties of the hybrid structures can be tailored, both geometrically and chemically, with high definition. Consequently, these materials possess exceptionally high potential to achieve optimal host response just with the electrode material.

Keywords: biocompatibility, neural cells, carbon nanotubes, carbon nanofibers, diamond-like carbon, nanodiamonds

\section{INTRODUCTION}

For therapeutic purposes, an accurate measurement of dopamine (DA) and glutamate (Glu) levels in situ would be highly desirable. Long-term DA recording systems have only begun to gain widespread use (Clark et al., 2010; Howe et al., 2013; Schwerdt et al., 2017). Unfortunately, with the carbon fiber microsensors currently in use, only moderate chemical selectivity is achieved (Roberts and Sombers, 2017; Rodeberg et al., 2017). The present-day Glu sensors enable shortterm usage and can perform measurements at second-to-second level in vivo (e.g., Dash et al., 2009; Hunsberger et al., 2015). However, there is a critical need for the improvement in the temporal 
resolution to monitor both the release and uptake of Glu: it has been suggested that the complete transport cycle takes only $70 \mathrm{~ms}$ (Wadiche et al., 1995).

We have developed a concept of hybrid carbon nanomaterials, referring to a new material where integration of two or more carbon allotropes with possible additions of selected metallic nanoparticles into a new hybrid has been carried out and which exhibits emerging properties that go significantly beyond those of its building blocks (reviewed by Laurila et al., 2017a). By utilizing these novel materials, we have achieved, for example, selective dopamine detection at the physiological concentration using carbon nanotube/tetrahedral amorphous carbon (CNT/taC)-hybrid (Sainio et al., 2015a; Palomäki et al., 2018) and ultrafast $(<0.05 \mathrm{~s})$ detection of glutamate using carbon nanofiber CNF/ta-C-hybrid (Isoaho et al., 2017). CNF/ta-C-hybrid shows prominence also in non-enzymatic detection of glutamate, although the response probably arises from changes in $\mathrm{pH}$ (Laurila, 2015; Sainio et al., 2015b). In conclusion, outstanding performance has been achieved in physiological saline. However, in order to achieve long-term measurements in vivo, the implant interface needs to be enhanced.

Biocompatibility is defined as the ability of materials to locally trigger and guide normal [scar-free] wound healing, reconstruction and tissue integration (Ratner, 2016). By this definition, majority of the current biomaterials are only biotolerable, i.e., able to reside in the body for long periods with only low degrees of inflammatory reaction. Accordingly, failure of integration has been proposed to be the main reason for sensor failure in vivo (Wisniewski and Reichert, 2000). Developing strategies for improved cell-material interaction is critical especially for all sensing and stimulating devices, such deep brain stimulator. Current strategies to enhance electrode integration into neural tissue exploit a protective layer or barrier on the surface. Such strategy jeopardizes the sensitivity and temporal resolution of a sensor and effectiveness of a stimulating device.

The typical outcome of host response of neural implants is the formation of glial-scar over the electrode surface, causing complication to reliable neuron-electrode coupling. Neural interfaces that maintain close physical coupling of neurons to an electrode surface are required for both implantable and in vitro neural recording electrode arrays. Currently, this is one of the major challenges in the designing of neural interfaces. Previous research shows that carbon nanomaterials reduce the functions of astrocytes (McKenzie et al., 2004). Nanostructures may enhance neuron-electrode coupling through suppression of scar tissue formation, it the structure reduces the glial cell coverage while preserving the high neuronal coverage (Chapman et al., 2015).

Nanostructured materials in neural interfaces need the ability to use both chemical and topographical cues to achieve the desired tissue response. It has been reported that random topographies, with a specific roughness value, affect adhesion and spreading of neuroglial cells (i.e., astrocytes) inducing the dissociation of the astrocytes from the neurons (Blumenthal et al., 2014; Chapman et al., 2015). Such response correlates either (i) with the topography-induced changes in the morphology of astrocytes (Blumenthal et al., 2014) or (ii) the topography-induced selection of the neurons over the astrocytes due to their different morphologies (Chapman et al., 2015).

Here, we demonstrate that it is possible to combine the properties of different carbon allotropes to obtain hybrid materials with enhanced neural response. Three following examples of the approach are given: (i) functionalized nanodiamonds (ND) on ta-C, (ii) multi-walled CNTs grown directly on top of ta-C, and (iii) CNFs synthesized on top of ta-C thin films. We have published some of the data regarding the biocompatibility of the hybrid structures earlier: ND/ta-C in Peltola et al. (2017a), CNT/ta-C in Palomäki et al. (2018), and $\mathrm{CNF} / \mathrm{ta}-\mathrm{C}$ in Isoaho et al. (2018b). Here we performed some additional viability and morphology measurements to enable better comparison of the different hybrid materials.

\section{MATERIALS AND METHODS}

\section{Sample Fabrication}

We fabricated three hybrid carbon structures: (i) functionalized ND/ta-C, (ii) CNT/ta-C, and (iii) CNF/ta-C. Thin film ta-C were investigated as a reference material.

\section{Fabrication of Thin Films}

$20 \mathrm{~nm}$ Ti adhesion layer (Laurila et al., 2014b) was deposited by direct-current magnetron sputtering on highly conductive (0.001-0.002 $\Omega \mathrm{cm}$ ) p-type (100) Si wafers (Ultrasil). Thin film ta-C of $7 \mathrm{~nm}$ were deposited on top of the Ti adhesion layer by filtered cathodic vacuum arc in the same deposition chamber. Further details are described by e.g., Palomäki et al. (2015) and Peltola et al. (2017a).

Platinum thin films were utilized as reference samples for platinum based CNF/ta-C hybrid. For this purpose, a $10 \mathrm{~nm} \mathrm{Pt}$ thin film was coated on Si using cathodic arc deposition.

\section{Fabrication ND/ta-C}

We investigated four types of functionalized NDs: zeta-positive $\mathrm{ND}_{\text {andante }}$ with amino and carboxyl functional groups, zeta positive amino functionalized $\mathrm{ND}_{\text {amine }}$, carboxyl functionalized zeta-negative $\mathrm{ND}_{\mathrm{vox}}$, and zeta positive hydrogen terminated $\mathrm{ND}_{\mathrm{H}}$ (Carbodeon uDiamonds, Carbodeon, Vantaa, Finland). A spraying technique was used for ND coating on ta-C substrates. Spraying solution was prepared from ND-water solutions with concentrations of $5 \mathrm{wt} \%\left(\mathrm{ND}_{\text {andante }}, \mathrm{ND}_{\text {vox }}\right), 0.99$ wt\% $\left(\mathrm{ND}_{\text {amine }}\right)$, and $2.5 \mathrm{wt} \%\left(\mathrm{ND}_{\mathrm{H}}\right)$. The ND-water solutions were diluted in ethanol and final concentration used for spraying was $0.05 \mathrm{wt} \%$. The spraying was done from a distance of $10 \mathrm{~cm}$ and the scanning was repeated 10 times. Pressurized air was utilized as carrying gas, the pressure being 3.5 bars.

\section{Fabrication CNT/ta-C-Hybrid}

A by RF-sputtering and e-beam evaporation were used for the deposition of a multilayer catalysts film of $0.2 \mathrm{~nm} \mathrm{Al}, 3 \mathrm{~nm} \mathrm{Co}$, and $3 \mathrm{~nm}$ Fe was on the top of ta-C. A low pressure chemical vapor deposition (CVD) reactor (Aixtron, Black Magic) was used. The samples were heated to $550^{\circ} \mathrm{C}$ process temperature using an electrical heated graphite holder in $\mathrm{NH}_{3}(250 \mathrm{sccm})$ at 10 mbar pressure for $10 \mathrm{~min}$ to reduce catalyst metals. Subsequent to 
chamber evacuation and refilling with $\mathrm{N}_{2}$ buffer gas (250 sccm) back to 10 mbar process pressure, a carbon precursor $\left(\mathrm{C}_{2} \mathrm{H}_{2}\right)$ was introduced into the chamber $(25 \mathrm{sccm})$ for another $10 \mathrm{~min}$ for the MWCNT synthesis while keeping the temperature at $550^{\circ} \mathrm{C}$.

\section{Fabrication of CNF/ta-C-Hybrid}

Prior to the CNF growth, a $10 \mathrm{~nm}$ Pt or $20 \mathrm{~nm}$ Ni catalyst layer was deposited on top of the ta- $\mathrm{C}$ thin films using cathodic arc deposition. The CNFs were grown with plasma-enhanced CVD at $750^{\circ} \mathrm{C}$ for $30(\mathrm{Pt}-\mathrm{CNF})$ or $60(\mathrm{Ni}-\mathrm{CNF})$ by utilizing $\mathrm{C}_{2} \mathrm{H}_{2}$ as a precursor. Further details are described by Sainio et al. (2015b).

\section{Cell Cultures and Analysis}

Prior to the cell culture experiments, the samples were sterilized in $70 \%$ ethanol for $10 \mathrm{~min}$. Cells were cultured in humidified incubator with $5 \% \mathrm{CO}_{2}$ in the air.

C6 (ATCCsCCL-107 ${ }^{\mathrm{TM}}$ ) rat glial cells and PC12 (adherent type, ATCCsCRL1721.1 ${ }^{\mathrm{TM}}$ ) rat neuroblastic cells were cultured in F12-K medium (or F12-K/DMEM without phenol red) supplemented with $2.5 \%$ fetal bovine serum (FBS) and $15 \%$ horse serum. Mouse neural stem cells (mNSC, ATCC ${ }^{\circledR}$ CRL2926 ${ }^{\mathrm{TM}}$ ) were cultured in Eagle's Minimum Essential Medium (without phenol red) supplemented with $4 \mathrm{mML}$-Glutamine and 10\% FBS. All media were supplemented with antibiotics, $100 \mathrm{IU} / \mathrm{ml}$ of penicillin and $100 \mu \mathrm{g} / \mathrm{ml}$ of streptomycin.

Samples $\left(1 \mathrm{~cm}^{2}\right)$ were placed on 12 -well plates and cells were seeded on the surfaces. The seeding densities for each cell line corresponded to the recommended seeding densities: approximately 30,000 cells $\mathrm{cm}^{-2}$ for mNSC and PC12 cells and 70,000 cells $\mathrm{cm}^{-2}$ for C6 cells.

\section{Staining}

Cells were cultured for $24 \mathrm{~h}$ on the surfaces. Cells were fixed with $4 \%$ paraformaldehyde fixation and permeabilized using $0.5 \%$ triton-X. Actin cytoskeleton was stained during $30 \mathrm{~min}$ incubation with phalloidin-568-label (Biotium 1:50 in PBS) and nuclei was stained using Vectrashield mounting medium with DAPI. Samples were coverslipped to prevent dehydration. Cells were imaged using Olympus BX51M microscope and Leica DCF420 digital microscope camera. Cell count was calculated from nuclei staining. Cell area was calculated directly from actin images and divided by the number of the cells calculated from nuclei staining. At least three images per sample type were analyzed. The software used for image processing was ImageJ Fiji.

\section{SEM}

For scanning electron microscopy, the cells were cultured on the surfaces for $24 \mathrm{~h}$ prior to fixation in $2.5 \%$ glutaraldehyde in PBS overnight at $4^{\circ} \mathrm{C}$. Subsequent to fixation, the samples were washed in PBS. Dehydration was performed in increasing ethanol series and completed using hexamethyldisilazane (SigmaAldrich). A chromium layer was coated on the samples to improve conductivity. Samples were inspected with a scanning electron microscope (JEOL JSM-6335F, field emission SEM).

\section{MTT}

3-(4,5-dimethylthiazol-2-yl) 2,5-diphenyltetrazolium bromide (MTT) assay was utilized to evaluate the viability of cells grown on ND/ta-C-hybrid samples. Cell were allowed to attach and grow for $24 \mathrm{~h}$ culture. Then, the samples were transferred to a clean 24-well plate in order to exclude the cells growing outside the samples on the plastic well and $1 \mathrm{mg} / \mathrm{ml}$ of MTT (Sigma Aldrich) was added in the medium. The samples were incubated for $3 \mathrm{~h}$ at $37^{\circ} \mathrm{C}$ in a humidified chamber. Cell culture medium was removed and MTT crystals were dissolved in $500 \mu \mathrm{l}$ of isopropanol. Dissolved MTT was transferred to another 24-well microplate for absorbance measurement at $570 \mathrm{~nm}$. Data was collected from triplicate samples using automated plate reader (FLUOstar Optima, Ortenberg, Germany).

\section{XTT}

MTT is not suitable for the viability assessment of MWCNTs as MTT-formazan crystals may react with MWCNTs (WörleKnirsch et al., 2006; Casey et al., 2007). 2,3-bis-(2-methoxy4-nitro-5-sulfophenyl)-2H-tetrazolium-5-carboxanilide (XTT) assay was used instead.

Samples were placed on multi-well plates and cells were cultured for $22 \mathrm{~h}$ (PC12, C6) or $48 \mathrm{~h}$ (mNSC). Samples were transferred to a clean 24-well plate and freshly preparer activated XTT solution (XTT cell viability kit, Biotium) was added to the medium (ratio 1:4) and incubated for $3.5 \mathrm{~h}$ before measurement of the absorbance signal at $450 \mathrm{~nm}$. Medium without phenol red was utilized. For PC12 and C6 cells a diluted concentration of serum $(7.5 \%$ of horse serum and $1.25 \%$ of FBS, i.e., $50 \%$ of the normal concentrations) was utilized with XTT as the kit instructions recommend medium concentration to be at most $10 \%$.

\section{RESULTS AND DISCUSSION}

We tested three types of hybrid carbon nanostructures, where a carbon nanostructure is combined with thin film ta-C. $\mathrm{ND}$ /ta-C-hybrid is a first generation hybrid carbon material, or pseudo hybrid, with no physical integration of the different carbon allotropes. CNT/ta-C-hybrid and CNF/ta-C-hybrid present second generation of hybrid carbon materials, where different carbon allotropes are physically integrated. The secondgeneration approach brings an important benefit for biomedical applications as the integrated structures are less likely to detach, reducing the risk for nanotoxicity.

\section{Neural Cells on ta-C}

Thin film ta-C is the substrate utilized in all of the hybrid structures presented in this paper. Thin film ta-C is characterized by excellent physical properties including high hardness and high elastic modulus as well as chemical inertness to any acids, alkaline solutions, and organic solvents. The ta- $\mathrm{C}$ films have a high $\mathrm{sp}^{3}$ content $(58.9 \%)$, and the surface region is significantly rich in $\mathrm{sp}^{2}$ (Sainio et al., 2016b). The films are extremely smooth with a roughness $\left(R_{\text {rms }}\right)$ of $0.81 \mathrm{~nm}$ (Wester et al., 2018) and the samples contain $<10$ at $\%$ of oxygen, the functional groups being ketone/aldehyde groups (Sainio et al., 2016b). Electrochemical properties of ta-C include extremely wide $(3.7 \mathrm{~V})$ and stable water window and relatively low capacitive background current (Kaivosoja et al., 2014). In addition, ta-C has facile electron 
transfer kinetics and high sensitivity, but no selectivity, toward dopamine (Laurila et al., 2014a).

Here we compared cell viability on untreated ta-C to poly-L-lysine (PLL) coated ta-C. Polylysine (PLL or poly-Dlysine, PDL) is commonly used as a coating material in the preparation of neuronal cultures (Yavin and Yavin, 1974). Interestingly, however, PLL increases only viability of mNSCs and glial C6 cells and not viability of neuroblastic PC12 cells (Figure 1). Moreover, the increase in the viability of mNSCs is not statistically significant. We have similar results also on mesenchymal stem cell differentiation into neurons: ta-C with PDL-coating increased glial fibrillary acidic protein (GFAP) levels of differentiating neurons indicated a presence of glial-like cells rather than neurons (not shown). This indicates that ta-C surface may be particularly suitable for direct neuronal interfacing. This is supported by a previous study showing that diamond film is suitable for direct neuronal interfacing, whereas glial cell growth required a protein coating (Bendali et al., 2014). However, this is not true for all carbon thin films. For example, a significant increase in PC12, C6, and mNSC viability is measured, for instance, on pyrolytic carbon with PLL coating compared to pyrolytic carbon without any coatings (Peltola et al., 2017b). Figure 1 presents images of $\mathrm{C} 6$ and $\mathrm{mNSC}$ on ta-C without any coating, showing well-adhered and spread cells.

\section{Neural Cells on ND/ta-C}

The protein-sized dimensions provides NDs the ability to influence on neuronal adhesion on a nanoscale subcellular level. The radial curvature of NDs is similar to proteins resulting in point-contact protein adsorption. Consequently, proteins are electrostatically adhered strongly to NDs but remain in their native structural and functional shape, as dictated by the hydrophobic force (Edgington et al., 2013). As an example, a previous study shows the bovine serum albumin (BSA) adsorbs with high affinity to NDs without conformational changes (Wang et al., 2011). Moreover, a small radius of curvature is reported to enhance the functional adsorption of (in particular) fragile globular proteins including vitronectin and fibronectin (Roach et al., 2006). Interestingly, previous research has further shown that ND layering provides an excellent growth substrate on various materials for functional neuronal networks and bypasses the necessity of protein coating (Thalhammer et al., 2010).

We examined the effect of surface functionalization of monodispersed NDs on ta-C on glial and neural cell viability. The investigated NDs had four types of functionalization: zeta-positive $\mathrm{ND}_{\text {andante }}$ with amino and carboxyl functional groups, zeta positive amino functionalized $\mathrm{ND}_{\text {amine, }}$ carboxyl functionalized zeta-negative $\mathrm{ND}_{\mathrm{vox}}$, and zeta positive hydrogen terminated $\mathrm{ND}_{\mathrm{H}}$. Details on $\mathrm{ND} /$ ta-C hybrid characterization are published previously (Peltola et al., 2017a). From sensing point, compared to ta-C, the ND/ta-C hybrid has enchased sensitivity toward dopamine and the detection limit is improved by two orders of magnitude (50 vs. $100 \mu \mathrm{M}$ ) (Peltola et al., 2017a).

We observed significant effect of the ND functionalization on the viability of cells (Figure 2 ). Some surfaces, namely $\mathrm{ND}_{\mathrm{H}}$ and $\mathrm{ND}_{\text {andate }}$, showed ability to specifically support neuroblastic cells. The viability PC12 cells and mNSCs increased by over $50 \%$ on
$\mathrm{ND}_{\mathrm{H}}$ surface and over $20 \%$ on $\mathrm{ND}_{\text {andate }}$ surface compared to ta$\mathrm{C}$ reference. In contrast, on $\mathrm{ND}_{\mathrm{vox}}$ and $\mathrm{ND}_{\text {amine }}$ surfaces, the viability of mNSCs reduced down to $90 \%$ and the viability of PC12 down to 50\% compared to ta-C reference. Interestingly, the viability of $\mathrm{C} 6$ cells was not affected by surface functionalization, suggesting that ND surfaces will not cause excess gliosis. Previous study shows that amino-functionalized surfaces direct neural differentiation to glial lineages (Yao et al., 2015), which is in agreement with the finding that $\mathrm{ND}_{\text {amine }}$ rather supports glial C6 cells than neuroblastic PC12 cells. However, the effects of surface chemistries on protein adsorption and cell adhesion on flat surfaces cannot be directly extrapolated to effects on nanostructured surfaces.

The different chemical functionalities influence the adsorption of macromolecules on the surfaces. According to a widely accepted assumption, proteins form a monolayer on the surfaces (Horbett, 1993). The Vroman effect suggests that small and abundant proteins will first cover a surface, but they will be replaced over time by proteins with stronger affinity for that particular surface (Vroman and Adams, 1969a,b). It is likely that the homogeneous $\mathrm{ND}_{\text {amine }}$ or $\mathrm{ND}_{\text {vox }}$ surfaces possess over dominance of certain proteins and lack of others, consequently affecting cell viability. $\mathrm{ND}_{\mathrm{H}}$ is homogeneous as well, but hydrogen functionalization does not provide specific binding cites for proteins. $\mathrm{ND}_{\text {andante, }}$ for comparison, posses both carboxyl and amino functionalizes and, consequently, the surface is heterogeneous. The heterogeneous surface does not result in similar over dominance of some proteins as a homogeneous surface may. However, heterogeneous surfaces may even repel protein adsorption (Shen and Zhu, 2016), which could be exploited in applications, which are sensitive for biofouling.

\section{Neural Cells on CNT/ta-C-Hybrid}

The size and shape of CNTs are similar to neuronal processes; they are strong yet flexible. High conductivity is an advantageous property as electrical stimulation has been shown to enhance nerve functions and regeneration (Heiduschka and Thanos, 1998; Kotwal and Schmidt, 2001).

Our process, where CNTs are grown on ta-C, has the benefit that the electrical connections between the carbon allotropes are well-established. When CNT coatings are fabricated with methods such as drop casting the electrical connections might not be well-established with the substrate. The multi-walled CNTs with a diameter of $20-40 \mathrm{~nm}$ and length $<10 \mu \mathrm{m}$ form a continuous film on top of the ta-C (Laurila, 2015; Laurila et al., 2015). Metallic elements, such as (Fe, Co)silicides and $\mathrm{Fe}-\mathrm{Co}$ particles formed during the activation of the catalyst and the growth of the nanotubes, remain in the material (Laurila, 2015; Laurila et al., 2015). Electrochemical properties of the $\mathrm{CNT} / \mathrm{ta}-\mathrm{C}$ hybrid include a relatively wide water window (2.7 V) (Sainio et al., 2015a). Furthermore, depending on the thickness of the underlying ta-C film, the CNT/ta-C hybrid has a relatively low detection limit for DA (42-77 nM), and more importantly, it provides excellent selectivity toward dopamine in the presence of ascorbic acid and uric acid at physiologically relevant concentrations using cyclic voltammetry (Palomäki et al., 2018). 

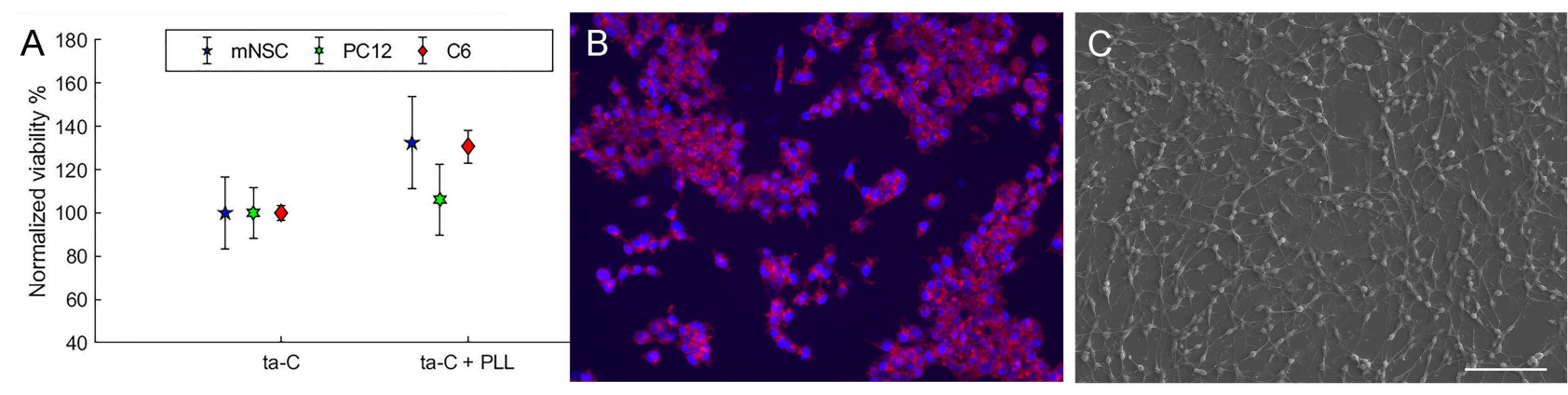

FIGURE 1 | (A) Shows the viability (MTT) of cells on ta-C with PLL coating compared to ta-C without any coatings. Viability is normalized to ta-C. (B) Shows mNSC on uncoated ta-C (actin on red, nuclei on blue), and (C) presents SEM image of C6 cells on uncoated ta-C (scale bar is $100 \mu \mathrm{m}$ ). Both cell types show typical morphology.

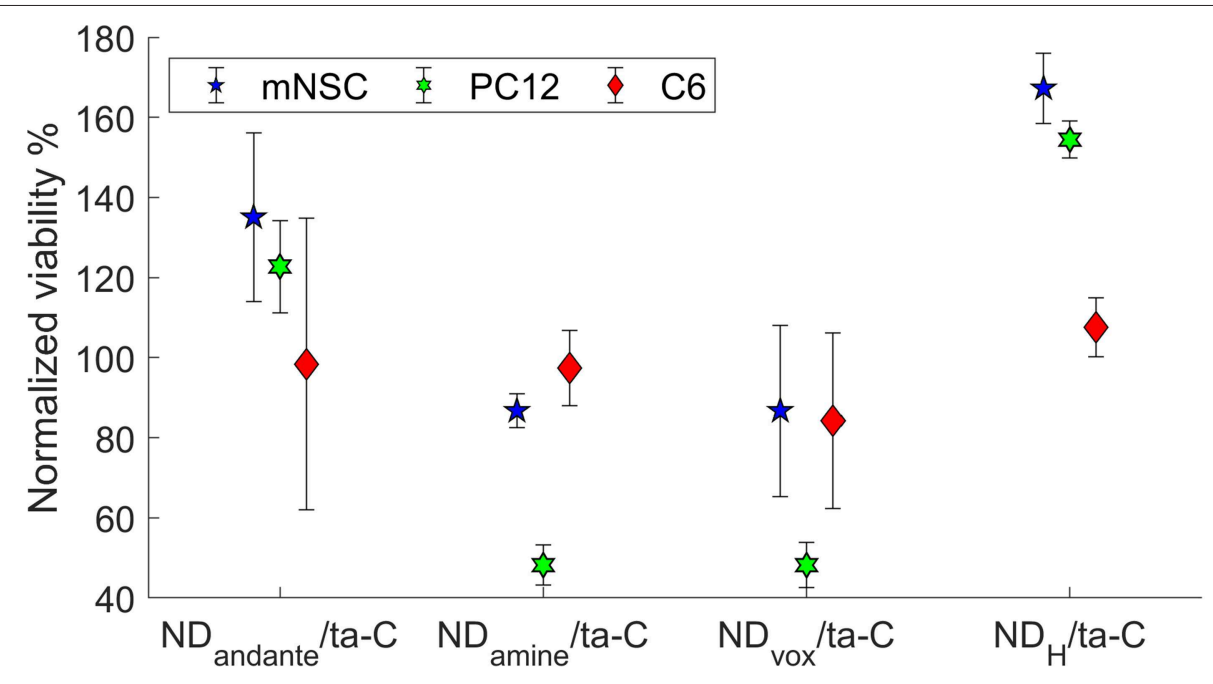

FIGURE 2 | Viability (MTT) of cells on functionalized hybrid ND/ta-C surfaces. Viability is normalized to ta-C. Modified from Peltola et al. (2017a).

Unfortunately, comparison of cell growth on different CNTs is challenging due to the limited amount of information provided. Too often, there is no information of the original seed material used for the growth of CNT or information of the size of the CNTs, or even if the CNT were single walled or multiwalled or opened (Laurila et al., 2017a). Moreover, common approaches for fabricating CNT based materials is mixing CNTs with a polymer or polyelectrode. Consequently, the cellular response is dominated by the polymer or polyelectrode rather than CNTs. Furthermore, for biocompatibility point of view, it is to be noted that impurities can constitute up to $20 \%$ of CNTs.

We evaluated the viability of glial (C6), neuroblastic (PC12), and neural stem cells on CNT/ta-C hybrid compared to thin film ta-C. Intriguingly, compared to ta-C thin films, CNT/taC-hybrid increased the viability of neuroblastic PC12 cells and decreases the viability of C6 glial cells (Figure 3A). The number of mNSCs showed no difference and Figure 3B shows that the mNSCs mostly grew in clusters and no significant differences between cell morphology on $\mathrm{CNT} / \mathrm{ta}-\mathrm{C}$ and ta- $\mathrm{C}$ thin film could be detected.

PC12 preference for CNT surface may be explained by the anisotropic nanotopography, which has been shown to be crucial to neuron growth and differentiation (Dang and Leong, 2007; Wang et al., 2012). The anisotropic structure aids cell migration and organization along the nerve fiber preferred direction. It has been shown that aligned and conductive fibrous scaffolds could provide better contact guidance effects in neurite outgrowth (Ghasemi-Mobarakeh et al., 2008; Zhang and Chang, 2008; Tonsomboon and Oyen, 2013; Masaeli et al., 2014; Zhang et al., 2016). Interestingly, neural stem cells elongate and their neurites outgrow along with the aligned fibers regardless of their diameter; however, nanofibers with a diameter of $250 \mathrm{~nm}$ promote cell differentiation compared to microfibers $(1.25 \mu \mathrm{m})$ (Yang et al., 2005). These CNT networks with well-established electrical connections to the substate have high potential for direct neural interfacing. However, the optimal CNT configuration is yet to be defined.

\section{Neural Cells on CNF/ta-C-Hybrid}

The CNF structure is a repetition of some type of graphite structure, such as bamboo-like, fishbone, platelet or ribbon types. The structure and dimensions of the CNFs are governed by the reactor type as well as the growth seed, temperature, and 


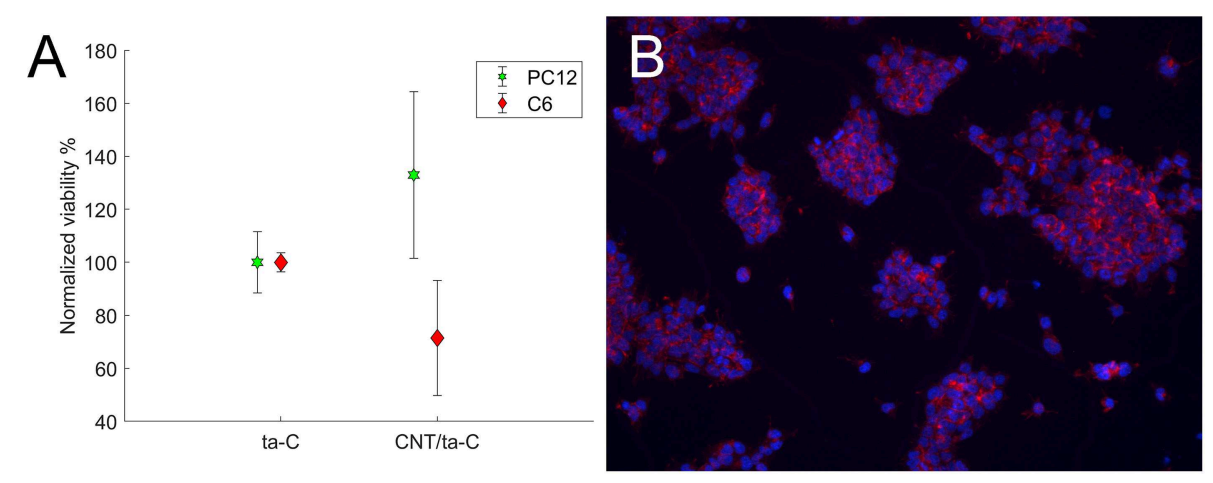

FIGURE 3 | (A) Shows viability (XTT) of cells on CNT/ta-C hybrid compared to ta-C. Viability is normalized to ta-C. (B) Shows mNSCs cultured on CNT/ta-C hybrid (actin red, nuclei blue).

time. For example, the presence of ta-C changes CNF structure from tubular like CNF to platelet like structure (Sainio et al., 2016a). The growth of CNF is a stochastic process and the consequential structure is highly heterogeneous. Accordingly, the interaction of cells and CNFs is rather complicated. However, this heterogeneous structure may better mimic the natural environment of the cells than highly ordered nanostructures.

Here we tested $\mathrm{Pt}$ and $\mathrm{Ni}$ based $\mathrm{CNF} / \mathrm{ta}-\mathrm{C}$ hybrid materials, which have been exhaustively characterized previously, Pt-CNFs by Laurila et al. (2017b) and Ni-CNFs by Sainio et al. (2016a). Both $\mathrm{CNF} /$ ta-C hybrids have a stacked platelet like structure. The structure of the Pt-CNF fibers somewhat less ordered than $\mathrm{Ni}-\mathrm{CNF}$ and the platelet edges are aligned toward the seed particle (Laurila et al., 2017b). Moreover, the Pt-CNS seems to have hollow or amorphous core, surrounded by several layers of stacked platelets (Laurila et al., 2017b). Furthermore, the dimensions of Ni-CNF and Pt-CNF are clearly different: Pt-CNFs have a smaller diameter, varying from 5 to $45 \mathrm{~nm}$ (Isoaho et al., 2018b), whereas Ni-CNFs are thicker, with a diameter from 50 to $500 \mathrm{~nm}$ (Sainio et al., 2016a). Further, Pt-CNF are shorter and have a height of 60-600 nm (Isoaho et al., 2018a), whereas NiCNF are typically taller, being closer to $1 \mu \mathrm{m}$ (Sainio et al., 2016a). $\mathrm{Pt}$ and ta-C thin films were used as reference samples. From biocompatibility point of view, Ni hypersensitivity is an issue, and $\mathrm{Pt}$ provides a better option. Indeed, complete removal of metal catalyst particles from CNFs and other carbon nanostructures is extremely difficult (Sainio et al., 2016c). In Pt-CNFs, the Pt remnants have application-specific role, enabling the detection of $\mathrm{H}_{2} \mathrm{O}_{2}$. This allows the detection of many biological analytes, such as glucose and glutamate, which are detected by utilizing an oxidase enzyme that catalyzes the formation of $\mathrm{H}_{2} \mathrm{O}_{2}$. We have shown that one of the most important benefits of Pt$\mathrm{CNF} / \mathrm{ta}-\mathrm{C}$ hybrid is that it provide ultrafast $(<0.05 \mathrm{~s})$ glutamate detection (Isoaho et al., 2017). Ni-CNF/ta-C hybrid, on the other hand, enhances dopamine detection $(1 \mu \mathrm{M})$ and selectivity in the presence of ascorbic acid compared to ta-C (Sainio et al., 2015b).

For yet an unknown reason, XTT did not give reliable values for viability of cells on CNFs. Although some insoluble tetrazolium salts such as MTT are known to interact with carbon nanostructures (Wörle-Knirsch et al., 2006), the interaction has not been an issue with the soluble tetrazolium salts such as XTT. However, the stacked platelet like structure has an excess amount of graphitic edge planes, which may interact with the XTT.

As an alternative, we utilized fluorescence microscopy images of cell nuclei for counting the cells and evaluating the viability. $\mathrm{Pt}$ thin films and ta-C samples were used as reference samples. We observed no statistically significant changes in cell count on the samples (Figure 4). As both C6 and mNSC show spreading on the surface and cell count is comparable to $\mathrm{Pt}$ and ta- $\mathrm{C}$ thin films, both CNF surfaces exhibit good biocompatibility.

The dimensions of CNF vary from a few tens of $\mathrm{nm}$ to hundreds of $\mathrm{nm}$. This range is particularly interesting as it matches biologically relevant dimensions of cell adhesions. A single integrin has a diameter of $10 \mathrm{~nm}$ (Nermut et al., 1988; Erb et al., 1997), whereas the adhesion complexes are rather large, micron, structures. The sub-adhesion integrin organization can divided into intermediate lenghts $(50-500 \mathrm{~nm})$ or at short lengths consisting a few integrins $(<50 \mathrm{~nm})$. Moreover, previous research shows a link in short $(<50 \mathrm{~nm})$ and intermediate $(50-$ $500 \mathrm{~nm}$ ) range integrin organization and the eventual signaling and anchoring capacity of adhesive complexes (Comisar et al., 2011). Interestingly, traction force increases with size for focal adhesions larger than $1 \mu \mathrm{m}$, whereas no correlation exists for smaller adhesions and the traction forces on these small focal adhesions can be very high (Tan et al., 2003).

Although no differences were observed in cell count, the adhesion and morphology of the cells is clearly affected by the CNFs. Most likely, the changes occur due to the different dimension of the nanofibers. Most apparent change is seen in the morphology of C6 cells (Figure 5). On Pt-CNF, which posses a smaller diameter compared to Ni-CNF, the $\mathrm{C} 6$ cells are spreading equally on all directions. In contrast, on Ni-CNF, the C6 cells are more oriented and possess an elongated morphology.

Interestingly, also the formation of filopodia is affected by the CNF dimensions. On Ni-CNFs, the cells possess an extensive amount of filopodias, whereas the number of filopodias on Pt$\mathrm{CNF}$ is increased only to some extent compared to ta-C or Pt thin films (Figure 5). However, the effect on filopodias is not 

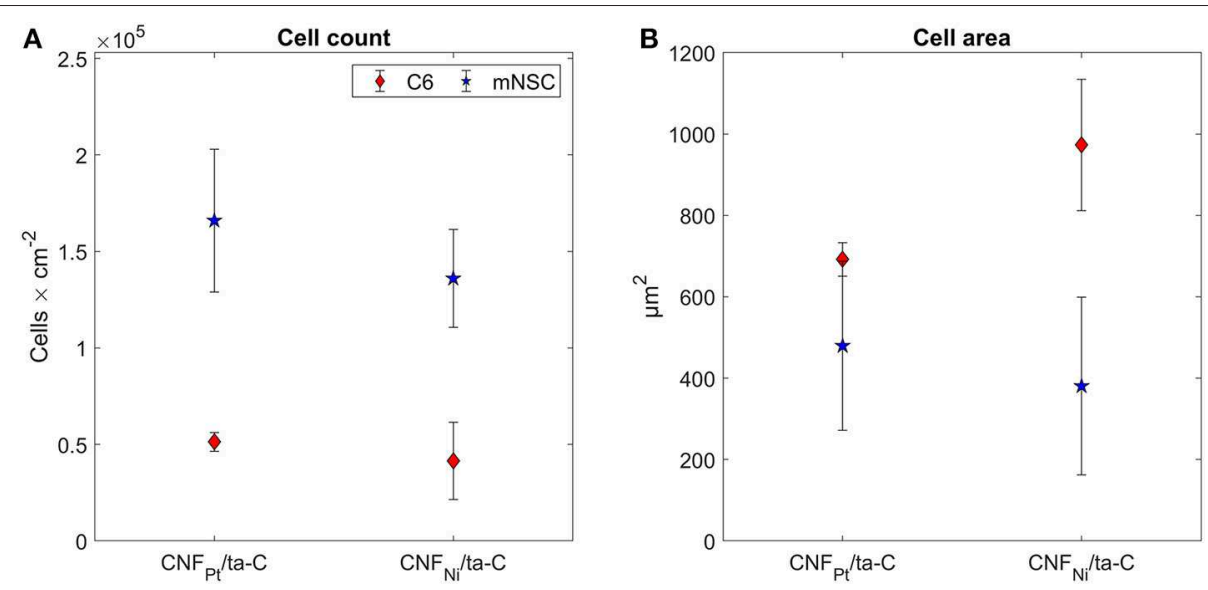

FIGURE 4 | (A) Cell count and (B) cell area on CNF/ta-C hybrid materials. Sample surface are in (A) corresponds to planar surface area, not the geometrical one. Modified from Isoaho et al. (2018b).

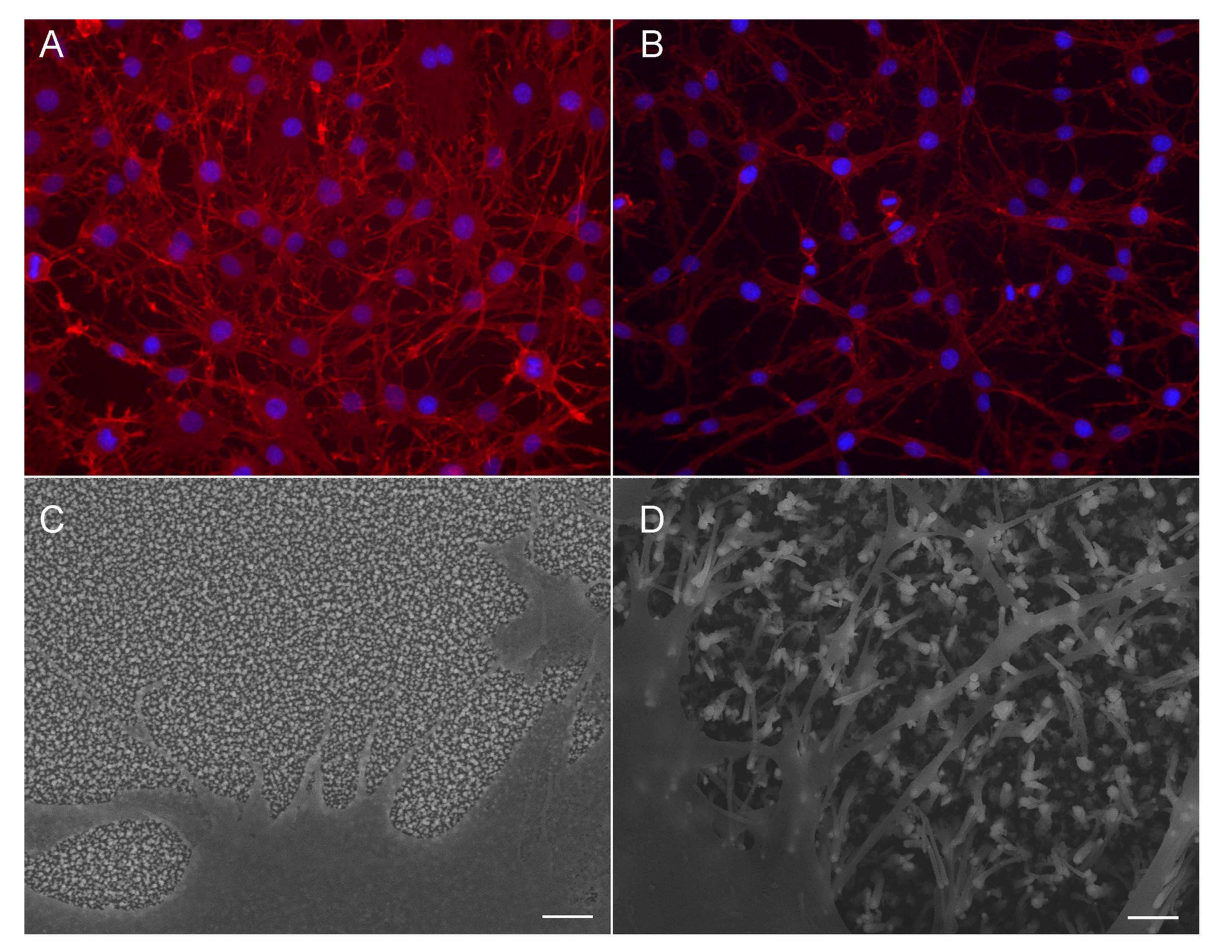

FIGURE 5 | C6 cells on $\mathrm{CNF}_{\mathrm{Pt}} /$ ta-C hybrid $\mathbf{( A , C )}$ and $\mathrm{CNF}_{\mathrm{Ni}} /$ ta-C hybrid $\mathbf{( B , D ) . ~ F l u o r e s c e n t ~ i m a g e ~} \mathbf{( A , B )}$ present actin on red and nuclei on blue. Cells on $\mathrm{CNF}_{\mathrm{Ni}} /$ ta-C hybrid present elongated morphology and extensive amount of filopodia compared to cells on $\mathbf{C N F}_{\mathrm{Pt}} /$ ta-C hybrid. Scale bar in (C,D) is $1 \mu \mathrm{m}$. (C,D) reproduced from Supplementary Material of Isoaho et al. (2018b) - Published by The Royal Society of Chemistry.

unexpected as the CNF diameters are comparable to cell adhesion dimensions. A filopodia has a diameter of 100-300 nm (Mattila and Lappalainen, 2008) and accordingly, a filopodia encounters just a single Ni-CNF fiber (or a bundle of collapsed Ni-CNFs). Previous studies also present a critical lateral interdistance of about $60-70 \mathrm{~nm}$ between integrin RGD ligands, above which integrin clustering and focal adhesion formation is hindered. If the spacing extends this critical distance, it inhibits cell attachment and spreading (Arnold et al., 2004; Selhuber-Unkel et al., 2010). This critical lateral distance probably follows the dimensions of ordered structures in the native extracellular matrix. For example, collagen fibrils have a $67 \mathrm{~nm}$ D-periodicity. As observed here, and reported before (Nguyen-Vu et al., 2007), the CNFs have a tendency to collapse into microbundles. Consequently, the distance between Ni-CNFs increases above the stated critical lateral interdistance. Moreover, the plentiful 
number of filopodia seen on Ni-CNF, may be explained by the cell adhesion forces. Previous research shows that cell adhesions smaller than $1 \mu \mathrm{m}^{2}$ are able to produce large adhesion forces (Tan et al., 2003).

In contrast, the Pt-CNFs posses smaller dimensions (5$45 \mathrm{~nm}$ ). Consequently, cell filopodia encounters several Pt-CNF fibers, allowing the cell to move flexibly. Nanoscale dimensions are important for the formation of proper synaptic connections. For example, a previous report shows that astrocytic syncytium level maximized at $50 \mathrm{~nm}$ dot arrays, compared to dot diameters ranging from 10 to $200 \mathrm{~nm}$ (Lee et al., 2014).

Considering cell response, it is possible that thin fibers in the range of a few dozen $\mathrm{nm}$ are more suitable option than thick fibers, with a diameter larger than $100 \mathrm{~nm}$. Nonetheless, it is yet to be investigated what kind of effects the dimension of CNFs will have on cell metabolism and functions. Here we observed that although the C6 cells grown on Pt-CNF appear to be spreading well (Figure 5), they are smaller compared to C6 cells grown on Ni-CNF, ta-C, or Pt thin films (Figure 4). It is assumed that that the CNF dimensions will cause further effects on cells, as the effect on cell size and morphology is so robust. In order to comprehend the impact of different fiber dimensions on cells and to achieve the optimal biological response, a more systematic study on the effect of different dimensions of CNFs is required.

\section{Benefits of Hybrid Structures}

Many of the hybrid structure growth processes are Complementary-Metal-Oxide-Semiconductor (CMOS) compatible and by utilizing different microsystem technologies it is possible to make devices out of these materials. Here we showed that these hybrid structures have high potential for direct neural interfacing. Consequently, these materials are highly attractive option for neural electrodes.

Table 1 summarizes the special features as well as the observations of neural cells on carbon nanostructure/ta-C hybrid materials. ND/ta-C hybrid with hydroxyl and carboxylamino functionalization as well as $\mathrm{CNT} / \mathrm{ta}-\mathrm{C}$ hybrid promotes the viability of neural PC12 cells and decreases viability of glial C6 cells. Consequently, these surfaces have potential for supporting neural differentiation over glial differentiation. As a result, tissue integration may be improved and glial scar formation prevented, guaranteeing an effective transfer of signal and stability of implant. CNF/ta-C hybrid structure has the advantage that the dimensions can be tailored. The size of the fibers affect cell adhesion and morphology, but further effects need to be investigated. A significant benefit of the presented hybrid structures is that we can tailor the properties of the structures relatively easily by adjusting processes, and it is possible to control both geometry and chemistry of the resulting typically have more well-defined structures, both geometrically and chemically. As show here, both the chemistry and physical dimension are significant for the cell adhesion, and whether the surface is preferred by neural or glial cells. Consequently, these surfaces have potential in improved tissue integration and prevention of the glial scar formation. The hybrid structures have exceptional potential for highly defined structures, both geometrically and chemically,
TABLE 1 | Special features and neural cell response on hybrid carbon materials.

\begin{tabular}{|c|c|c|}
\hline $\begin{array}{l}\text { Hybrid } \\
\text { material }\end{array}$ & Special features & Neural cell response \\
\hline ND/ta-C & $\begin{array}{l}\text { ND size and curvature } \\
\text { comparable to proteins. }\end{array}$ & $\begin{array}{l}\text { Functionalization with hydrogen } \\
\text { or mixed functionalization with } \\
\text { carboxyl-amino group resulted in } \\
\text { increased viability of neuroblastic } \\
\text { cells and neural PC12 cells. }\end{array}$ \\
\hline CNT/ta-C & $\begin{array}{l}\text { Anisotropic topography and CNT } \\
\text { network conductivity. }\end{array}$ & $\begin{array}{l}\text { CNTs promoted the viability of } \\
\text { neural PC12 cell and decreased } \\
\text { the viability of glial C6 cells } \\
\text { compared to ta-C surface. }\end{array}$ \\
\hline CNF/ta-C & $\begin{array}{l}\text { CNF diameter can be tailored } \\
\text { and is comparable to cell } \\
\text { adhesion dimensions. }\end{array}$ & $\begin{array}{l}\text { Cell morphology and size are } \\
\text { affected by the CNF dimensions. } \\
\text { No difference in cell count was } \\
\text { observed. }\end{array}$ \\
\hline
\end{tabular}

enabling optimization of the cellular response. Consequently, these materials posses exceptionally high potential to achieve direct neural interfacing.

\section{CONCLUSIONS}

We have demonstrated that we can modify cellular response just with the electrode material. This is highly desirable for sensor applications requiring fast response times. For example, the fluctuation of neurotransmitters is in ms scale, and any protective layer on the electrode would cause a diffusion barrier and consequent loss of temporal resolution. Particularly surfaces supporting neural cells over glial differentiation, namely ND/ta-C with hydrogen or mixed (carboxyl/amino) functionalization and $\mathrm{CNT} / \mathrm{ta}-\mathrm{C}$, have high prominence in direct neural interfacing. These surfaces have potential in improved tissue integration and prevention of the glial scar formation therefore guaranteeing an effective transfer of signal and stability of implant. Due to the high ability to tailor the dimensions of $\mathrm{CNF} / \mathrm{ta}-\mathrm{C}$, these materials also exhibit significant potential in direct interfacing. However, a more systematic study is required to understand the effects of different fiber sizes on cells to find the optimal dimensions for biological response.

\section{DATA AVAILABILITY}

The datasets generated for this study are available on request to the corresponding author.

\section{AUTHOR CONTRIBUTIONS}

EP designed and conducted the experiments and wrote the manuscript.

\section{FUNDING}

This work was supported by Academy of Finland (\#274670). 


\section{ACKNOWLEDGMENTS}

Several people have contributed greatly to the results described in this manuscript. MSc Elsi Mynttinen (Aalto University, Espoo, Finland) is acknowledged for the MSC experiments on ta-C; Prof. Jari Koskinen and MSc Niklas Wester (Aalto University, Espoo, Finland) for the synthesis of ta-C thin films, Professor

\section{REFERENCES}

Arnold, M., Cavalcanti-Adam, E. A., Glass, R., Blümmel, J., Eck, W., Kantlehner, M., et al. (2004). Activation of integrin function by nanopatterned adhesive interfaces. Chemphyschem 5, 383-388. doi: 10.1002/cphc.200301014

Bendali, A., Agnès, C., Meffert, S., Forster, V., Bongrain, A., Arnault, J. C., et al. (2014). Distinctive glial and neuronal interfacing on nanocrystalline diamond. PLoS ONE 9:e92562. doi: 10.1371/journal.pone.0092562

Blumenthal, N. R., Hermanson, O., Heimrich, B., and Shastri, V. P. (2014). Stochastic nanoroughness modulates neuron-astrocyte interactions and function via mechanosensing cation channels. PNAS 111, 16124-16129. doi: 10.1073/pnas.1412740111

Casey, A., Herzog, E., Davoren, M., Lyng, F. M., Byrne, H. J., and Chambers, G. (2007). Spectroscopic analysis confirms the interactions between single walled carbon nanotubes and various dyes commonly used to assess cytotoxicity. Carbon 45, 1425-1432. doi: 10.1016/j.carbon.2007.03.033

Chapman, C. A., Chen, H., Stamou, M., Biener, J., Biener, M. M., Lein, P. J., et al. (2015). Nanoporous gold as a neural interface coating: effects of topography, surface chemistry, and feature size. ACS Appl. Mater. Interfaces 7, 7093-7100. doi: 10.1021/acsami.5b00410

Clark, J. J., Sandberg, S. G., Wanat, M. J., Gan, J. O., Horne, E. A., Hart, A. S., et al. (2010). Chronic microsensors for longitudinal, subsecond dopamine detection in behaving animals. Nat. Met. 7, 126-129. doi: 10.1038/nmeth.1412

Comisar, W. A., Mooney, D. J., and Linderman, J. J. (2011). Integrin organization: linking adhesion ligand nanopatterns with altered cell responses. J. Theor. Biol. 274, 120-130. doi: 10.1016/j.jtbi.2011.01.007

Dang, J. M., and Leong, K. W. (2007). Myogenic induction of aligned mesenchymal stem cell sheets by culture on thermally responsive electrospun nanofibers. $A d v$. Mater. 19, 2775-2779. doi: 10.1002/adma.200602159

Dash, M. B., Douglas, C. L., Vyazovskiy, V. V., Cirelli, C., and Tononi, G. (2009). Long-term homeostasis of extracellular glutamate in the rat cerebral cortex across sleep and waking states. J. Neurosci. 29, 620-629. doi: 10.1523/JNEUROSCI.5486-08.2009

Edgington, R. J., Thalhammer, A., Welch, J. O., Bongrain, A., Bergonzo, P., Scorsone, E., et al. (2013). Patterned neuronal networks using nanodiamonds and the effect of varying nanodiamond properties on neuronal adhesion and outgrowth. J. Neur. Eng. 10:056022. doi: 10.1088/1741-2560/10/5/056022

Erb, E. M., Tangemann, K., Bohrmann, B., Müller, B., and Engel, J. (1997). Integrin $\alpha \operatorname{IIb} \beta 3$ reconstituted into lipid bilayers is nonclustered in its activated state but clusters after fibrinogen binding. Biochemistry 36, 7395-7402. doi: $10.1021 /$ bi9702187

Ghasemi-Mobarakeh, L., Prabhakaran, M. P., Morshed, M., Nasr-Esfahani, M. H., and Ramakrishna, S. (2008). Electrospun poly ( $\varepsilon$-caprolactone)/gelatin nanofibrous scaffolds for nerve tissue engineering. Biomaterials 29, 4532-4539. doi: 10.1016/j.biomaterials.2008.08.007

Heiduschka, P., and Thanos, S. (1998). Implantable bioelectronic interfaces for lost nerve functions. Prog. Neurobiol. 55, 433-461. doi: 10.1016/S0301-0082(98)00013-6

Horbett, T. A. (1993). Principles underlying the role of adsorbed plasma proteins in blood interactions with foreign materials. Cardiovasc. Pathol. 2, 137-148. doi: 10.1016/1054-8807(93)90054-6

Howe, M. W., Tierney, P. L., Sandberg, S. G., Phillips, P. E., and Graybiel, A. M. (2013). Prolonged dopamine signalling in striatum signals proximity and value of distant rewards. Nature 500, 575-579. doi: 10.1038/nature 12475

Hunsberger, H. C., Weitzner, D. S., Rudy, C. C., Hickman, J. E., Libell, E. M., Speer, R. R., et al. (2015). Riluzole rescues glutamate alterations, cognitive deficits,
Krisztian Kordas and Mr. Olli Pitkänen (University of Oulu, Finland) for the growth of CNTs; Dr. Sami Sainio (Aalto University, Espoo, Finland) for ND deposition as well as for the growth of CNFs in collaboration with Dr. Jessica Koehne and Dr. Meyya Meyyappan (NASA Ames Research Center, USA). Prof. Tomi Laurila developed the concept of hybrid carbon materials. and tau pathology associated with P301L tau expression. J. Neurochem. 135, 381-394. doi: $10.1111 /$ jnc. 13230

Isoaho, N., Peltola, E., Sainio, S., Koskinen, J., and Laurila, T. (2018b). Pt-grown carbon nanofibers for enzymatic glutamate biosensors and assessment of their biocompatibility. RSC Adv. 8, 35802-35812. doi: 10.1039/C8RA07766E

Isoaho, N., Peltola, E., Sainio, S., Wester, N., Protopopova, V., Wilson, B. P., et al. (2017). Carbon nanostructure based platform for enzymatic glutamate biosensors. J. Phys. Chem. C 121, 4618-4626. doi: 10.1021/acs.jpcc.6b10612

Isoaho, N., Sainio, S., Wester, N., Botello, L., Johansson, L. S., Peltola, E., et al. (2018a). Pt-grown carbon nanofibers for detection of hydrogen peroxide. RSC Adv. 8, 12742-12751. doi: 10.1039/C8RA01703D

Kaivosoja, E., Sainio, S., Lyytinen, J., Palomäki, T., Laurila, T., Kim, S. I., et al. (2014). Carbon thin films as electrode material in neural sensing. Surf. Coat. Technol. 259, 33-38. doi: 10.1016/j.surfcoat.2014.07.056

Kotwal, A., and Schmidt, C. E. (2001). Electrical stimulation alters protein adsorption and nerve cell interactions with electrically conducting biomaterials. Biomaterials 22, 1055-1064. doi: 10.1016/S0142-9612(00)00344-6

Laurila, T. (2015). Hybrid carbon nanomaterials for electrochemical detection of biomolecules. Phys. Scr. 90:094006. doi: 10.1088/0031-8949/90/9/094006

Laurila, T., Protopopova, V., Rhode, S., Sainio, S., Palomäki, T., Moram, M., et al. (2014a). New electrochemically improved tetrahedral amorphous carbon films for biological applications. Diam. Relat. Mater. 49, 62-71. doi: 10.1016/j.diamond.2014.08.007

Laurila, T., Rautiainen, A., Sintonen, S., Jiang, H., Kaivosoja, E., and Koskinen, J. (2014b). Diamond-like carbon (DLC) thin film bioelectrodes: effect of thermal post-treatments and the use of Ti adhesion layer. Mater. Sci. Eng. C 34, 446-454. doi: 10.1016/j.msec.2013.09.035

Laurila, T., Sainio, S., and Caro, M. A. (2017a). Hybrid carbon based nanomaterials for electrochemical detection of biomolecules. Prog. Mater. Sci. 88, 499-594. doi: 10.1016/j.pmatsci.2017.04.012

Laurila, T., Sainio, S., Jiang, H., Isoaho, N., Koehne, J. E., Etula, J., et al. (2017b). Application-specific catalyst layers: Pt-containing carbon nanofibers for hydrogen peroxide detection. ACS Omega 2, 496-507. doi: 10.1021/acsomega.6b00441

Laurila, T., Sainio, S., Jiang, H., Palomäki, T., Pitkänen, O., Kordas, K., et al. (2015). Multi-walled carbon nanotubes (MWCNTs) grown directly on tetrahedral amorphous carbon (ta-C): an interfacial study. Diam. Relat. Mater. 56, 54-59. doi: 10.1016/j.diamond.2015.05.005

Lee, C. H., Cheng, Y. W., and Huang, G. S. (2014). Topographical control of cellcell interaction in C6 glioma by nanodot arrays. Nanoscale Res. Lett. 9:250. doi: 10.1186/1556-276X-9-250

Masaeli, E., Wieringa, P. A., Morshed, M., Nasr-Esfahani, M. H., Sadri, S., van Blitterswijk, C. A., et al. (2014). Peptide functionalized polyhydroxyalkanoate nanofibrous scaffolds enhance Schwann cells activity. Nanomedicine 10, 1559-1569. doi: 10.1016/j.nano.2014.04.008

Mattila, P. K., and Lappalainen, P. (2008). Filopodia: molecular architecture and cellular functions. Nat. Rev. Mol. Cell Biol. 9, 446-454. doi: 10.1038/nrm2406

McKenzie, J. L., Waid, M. C., Shi, R., and Webster, T. J. (2004). Decreased functions of astrocytes on carbon nanofiber materials. Biomaterials 25, 1309-1317. doi: 10.1016/j.biomaterials.2003.08.006

Nermut, M. V., Green, N. M., Eason, P., Yamada, S. S., and Yamada, K. M. (1988). Electron microscopy and structural model of human fibronectin receptor. EMBO J. 7, 4093-4099. doi: 10.1002/j.1460-2075.1988.tb03303.x

Nguyen-Vu, T. B., Chen, H., Cassell, A. M., Andrews, R. J., Meyyappan, M., and Li, J. (2007). Vertically aligned carbon nanofiber architecture as a multifunctional 3-D neural electrical interface. IEEE Trans. Biomed. Eng. 54, 1121-1128. doi: 10.1109/TBME.2007.891169 
Palomäki, T., Chumillas, S., Sainio, S., Protopopova, V., Kauppila, M., Koskinen, J., et al. (2015). Electrochemical reactions of catechol, methylcatechol and dopamine at tetrahedral amorphous carbon (ta-C) thin film electrodes. Diam. Rel. Mater. 59, 30-39. doi: 10.1016/j.diamond.2015.09.003

Palomäki, T., Peltola, E., Sainio, S., Wester, N., Pitkänen, O., Kordas, K., et al. (2018). Unmodified and multi-walled carbon nanotube modified tetrahedral amorphous carbon (ta-C) films as in vivo sensor materials for sensitive and selective detection of dopamine. Biosens. Bioelectron. 118, 23-30. doi: 10.1016/j.bios.2018.07.018

Peltola, E., Heikkinen, J. J., Sovanto, K., Sainio, S., Aarva, A., Franssila, S., et al. (2017b). SU-8 based pyrolytic carbon for the electrochemical detection of dopamine. J. Mat. Chem. B 5, 9033-9044. doi: 10.1039/C7TB02469J

Peltola, E., Wester, N., Holt, K. B., Johansson, L. S., Koskinen, J., Myllymäki, V., et al. (2017a). Nanodiamonds on tetrahedral amorphous carbon significantly enhance dopamine detection and cell viability. Biosens. Bioelectron. 88, 273-282. doi: 10.1016/j.bios.2016.08.055

Ratner, B. D. (2016). A pore way to heal and regenerate: 21 st century thinking on biocompatibility. Regen. Biomater. 3, 107-110. doi: 10.1093/rb/rbw006

Roach, P., Farrar, D., and Perry, C. C. (2006). Surface tailoring for controlled protein adsorption: effect of topography at the nanometer scale and chemistry. JACS 128, 3939-3945. doi: 10.1021/ja056278e

Roberts, J. G., and Sombers, L. A. (2017). Fast-scan cyclic voltammetry: chemical sensing in the brain and beyond. Anal. Chem. 90, 490-504. doi: 10.1021/acs.analchem.7b04732

Rodeberg, N. T., Sandberg, S. G., Johnson, J. A., Phillips, P. E., and Wightman, R. M. (2017). Hitchhiker's guide to voltammetry: acute and chronic electrodes for in vivo fast-scan cyclic voltammetry. ACS Chem. Neurosci. 8, 221-234. doi: 10.1021/acschemneuro.6b00393

Sainio, S., Jiang, H., Caro, M. A., Koehne, J., Lopez-Acevedo, O., Koskinen, J., et al. (2016a). Structural morphology of carbon nanofibers grown on different substrates. Carbon 98, 343-351. doi: 10.1016/j.carbon.2015.11.021

Sainio, S., Nordlund, D., Caro, M. A., Gandhiraman, R., Koehne, J., Wester, N., et al. (2016b). Correlation between sp3-to-sp2 ratio and surface oxygen functionalities in tetrahedral amorphous carbon (ta-C) thin film electrodes and implications of their electrochemical properties. J. Phys. Chem. C 120, 8298-8304. doi: 10.1021/acs.jpcc.6b02342

Sainio, S., Nordlund, D., Gandhiraman, R., Jiang, H., Koehne, J., Koskinen, J., et al. (2016c). What does nitric acid really do to carbon nanofibers? J. Phys. Chem. C 120, 22655-22662. doi: 10.1021/acs.jpcc.6b06353

Sainio, S., Palomäki, T., Rhode, S., Kauppila, M., Pitkänen, O., Selkälä, T., et al. (2015a). Carbon nanotube (CNT) forest grown on diamond-like carbon (DLC) thin films significantly improves electrochemical sensitivity and selectivity towards dopamine. Sens. Actuat. B Chem. 211, 177-186. doi: 10.1016/j.snb.2015.01.059

Sainio, S., Palomäki, T., Tujunen, N., Protopopova, V., Koehne, J., Kordas, K., et al. (2015b). Integrated carbon nanostructures for detection of neurotransmitters. Mol. Neurobiol. 52, 859-866. doi: 10.1007/s12035-015-9233-Z

Schwerdt, H. N., Shimazu, H., Amemori, K. I., Amemori, S., Tierney, P. L., Gibson, D. J., et al. (2017). Long-term dopamine neurochemical monitoring in primates. PNAS 114, 13260-13265. doi: 10.1073/pnas.1713756114

Selhuber-Unkel, C., Erdmann, T., Lopez-Garcia, M., Kessler, H., Schwarz, U. S., and Spatz, J. P. (2010). Cell adhesion strength is controlled by intermolecular spacing of adhesion receptors. Biophys. J. 98, 543-551. doi: 10.1016/j.bpj.2009.11.001

Shen, L., and Zhu, J. (2016). Heterogeneous surfaces to repel proteins. Adv. Colloid Interface Sci. 228, 40-54. doi: 10.1016/j.cis.2015.11.008

Tan, J. L., Tien, J., Pirone, D. M., Gray, D. S., Bhadriraju, K., and Chen, C. S. (2003). Cells lying on a bed of microneedles: an approach to isolate mechanical force. PNAS 100, 1484-1489. doi: 10.1073/pnas.0235407100
Thalhammer, A., Edgington, R. J., Cingolani, L. A., Schoepfer, R., and Jackman, R. B. (2010). The use of nanodiamond monolayer coatings to promote the formation of functional neuronal networks. Biomaterials 31, 2097-2104. doi: 10.1016/j.biomaterials.2009.11.109

Tonsomboon, K., and Oyen, M. L. (2013). Composite electrospun gelatin fiberalginate gel scaffolds for mechanically robust tissue engineered cornea. J. Mech. Behav. Biomed. Mater. 21, 185-194. doi: 10.1016/j.jmbbm.2013.03.001

Vroman, L., and Adams, A. L. (1969a). Identification of rapid changes at plasmasolid interfaces. J. Biomed. Mater. Res. 3, 43-67. doi: 10.1002/jbm.820030106

Vroman, L., and Adams, A. L. (1969b). Identification of adsorbed protein films by exposure to antisera and water vapour. J. Biomed. Mater. Res. 3, 669-671. doi: $10.1002 /$ jbm. 820030410

Wadiche, J. I., Arriza, J. L., Amara, S. G., and Kavanaugh, M. P. (1995). Kinetics of a human glutamate transporter. Neuron 14, 1019-1027. doi: 10.1016/0896-6273(95)90340-2

Wang, H. D., Niu, C. H., Yang, Q., and Badea, I. (2011). Study on protein conformation and adsorption behaviors in nanodiamond particle-protein complexes. Nanotechnology 22:145703. doi: 10.1088/0957-4484/22/14/145703

Wang, P. Y., Thissen, H., and Tsai, W. B. (2012). The roles of RGD and grooved topography in the adhesion, morphology, and differentiation of $\mathrm{C} 2 \mathrm{C} 12$ skeletal myoblasts. Biotech. Bioeng. 10, 2104-2115. doi: 10.1002/bit.24452

Wester, N., Etula, J., Lilius, T., Sainio, S., Laurila, T., and Koskinen, J. (2018). Selective detection of morphine in the presence of paracetamol with anodically pretreated dual layer Ti/tetrahedral amorphous carbon electrodes. Electrochem. Commun. 86, 166-170. doi: 10.1016/j.elecom.2017.12.014

Wisniewski, N., and Reichert, M. (2000). Methods for reducing biosensor membrane biofouling. Colloids Surf. B 18, 197-219. doi: 10.1016/S0927-7765(99)00148-4

Wörle-Knirsch, J. M., Pulskamp, K., and Krug, H. F. (2006). Oops they did it again! Carbon nanotubes hoax scientists in viability assays. Nano Lett. 6, 1261-1268. doi: $10.1021 /$ nl060177c

Yang, F., Murugan, R., Wang, S., and Ramakrishna, S. (2005). Electrospinning of nano/micro scale poly (L-lactic acid) aligned fibers and their potential in neural tissue engineering. Biomaterials 26, 2603-2610. doi: 10.1016/j.biomaterials.2004.06.051

Yao, S., Liu, X., He, J., Wang, X., Wang, Y., and Cui, F. Z. (2015). Ordered self-assembled monolayers terminated with different chemical functional groups direct neural stem cell linage behaviours. Biomed. Mater. 11:014107. doi: 10.1088/1748-6041/11/1/014107

Yavin, E., and Yavin, Z. (1974). Attachment and culture of dissociated cells from rat embryo cerebral hemispheres on polylysine-coated surface. J. Cell Biol. 62:540. doi: $10.1083 /$ jcb.62.2.540

Zhang, D., and Chang, J. (2008). Electrospinning of three-dimensional nanofibrous tubes with controllable architectures. Nano Lett. 8, 3283-3287. doi: $10.1021 / \mathrm{nl} 801667 \mathrm{~s}$

Zhang, K., Zheng, H., Liang, S., and Gao, C. (2016). Aligned PLLA nanofibrous scaffolds coated with graphene oxide for promoting neural cell growth. Acta Biomater. 37, 131-142. doi: 10.1016/j.actbio.2016.04.008

Conflict of Interest Statement: The author declares that the research was conducted in the absence of any commercial or financial relationships that could be construed as a potential conflict of interest.

Copyright (c) 2019 Peltola. This is an open-access article distributed under the terms of the Creative Commons Attribution License (CC BY). The use, distribution or reproduction in other forums is permitted, provided the original author(s) and the copyright owner(s) are credited and that the original publication in this journal is cited, in accordance with accepted academic practice. No use, distribution or reproduction is permitted which does not comply with these terms. 